\title{
Chile se pone de pie otra vez
}

\author{
HUMBERTO REYES B.
}

\section{Chile: Standing up again}

One of the biggest earthquakes recorded in human history has recently devastated a large part of the Chilean territory and, followed by a Tsunami, destroyed cities, seaports, fishermen's coves, bridges, and countryside houses. This cataclysm affected a large proportion of our population, leaving homeless families, no working tools nor work places, hospitals, schools, public buildings, museums. However, the loss of human lives was small compared to similar disasters. It destroyed part of the national heritage as well as damaged people's living conditions. A national movement started immediately to help and recover, and international resources, both human and technological, were also set in motion. As after previous earthquakes in Chile, young M.D.'s and medical students were organized in voluntary groups backed by institutions or by their own organizations and went from large cities as Santiago and others to provide medical and psychological care to those in most need. Young members and students of other health professions (nurses, physical therapists, etc.) were included in these groups or worked in their own ones. National and international experience indicates that the forthcoming months require special care of psychological reactions and sequelae (post traumatic stress symptoms) and health consequences after water pollution, restrictions in housing and deteriorated sanitary conditions. Nevertheless, our country will stand up once more.

(Rev Med Chile 2010; 138: 267-269).

Key words: Chile; Disasters; Earthquakes; Students, health occupations; Tsunamis.

$\mathrm{E}$ n la madrugada del 27 de febrero de 2010, Chile fue estremecido por un terremoto de extraordinaria intensidad y duración, que tuvo su epicentro frente a Cobquecura, en la $8^{\mathrm{a}}$ Región, y dañó ciudades, pueblos y campos desde Valparaíso hasta Valdivia. Pocos minutos después, oleadas sucesivas de un maremoto azotaron la costa en una extensión similar, anegando puertos y caletas pesqueras en el borde continental, y llegó hasta la isla de Juan Fernández. Las comunicaciones terrestres y telefónicas se interrumpieron, aislando ciudades y familias. La televisión internacional y la internet difundieron la noticia y en pocas horas el desastre se conoció mundialmente. Tal fue la intensidad del sismo que el eje del planeta sufrió un cambio. El corte de la energía eléctrica y del suministro de gas y agua potable agregaron dramatismo a los daños materiales. Sin embargo, la pérdida de vidas humanas fue afortunadamen- te menor que la sufrida en terremotos previos, en Chile y otros lugares. Una alta proporción de nuestra población quedó desamparada, a la intemperie, en muchos casos sin alimentos y tristemente expuesta a actos de pillaje que afectaron la propiedad privada de empresas y personas. Instituciones públicas y privadas reaccionaron de inmediato, asumiendo la tarea de rescatar cuerpos (vivos o muertos) bajo los escombros o en el océano, de auxiliar a los damnificados, restablecer las comunicaciones y el suministro de alimentos, los recursos de protección y recuperación de salud, albergues, seguridad pública. Desde diversos países se recibió ayuda material y humana, además de expresiones de cariño y apoyo espiritual.

En las zonas más afectadas, los médicos y el personal de la salud también sufrieron angustia hasta conocer la situación de sus familias, de sus casas, sus hospitales y consultorios. Muchos vie- 
ron desaparecer o dañarse gravemente sus casas habitación, además de sus hospitales y centros de atención al público. Más aún, las réplicas del terremoto, reiteradas día y noche y hasta el momento en que escribo estas líneas, contribuyen a mantener una situación de calamidad pública. A pesar de ello, horas después del sismo, el personal de salud estaba en sus puestos y se organizaron las labores necesarias para contribuir a la calma de la población y la protección de sus condiciones de salud. En pocos días, misiones de ayuda voluntaria surgieron en Santiago y otras ciudades para acudir a las localidades más dañadas, llevando ayuda en especies o contribuyendo con sus conocimientos técnicos y profesionales. Entre ellas, intervinieron grupos de médicos jóvenes, internos y alumnos de Escuelas de Medicina, organizados por instituciones públicas y privadas, o por sus Centros de Alumnos, extendidas a las diversas profesiones de la salud. El artículo que destacamos como "Perspectiva" en este número de la Revista Médica de Chile ${ }^{1}$ es un relato emotivo de la experiencia vivida por uno de estos grupos de ayuda humanitaria y seguramente retrata lo que otros también han vivido. Será un testimonio de cómo, una vez más, la sociedad chilena es apoyada por quienes han recibido o están recibiendo formación en profesiones con responsabilidad social y la afrontan con encomiable sensatez, entusiasmo y cariño.

Hace casi cincuenta años, el 22 de mayo de 1960 , otro terremoto, de mayor intensidad y duración aún que el actual, destruyó gran parte del sur de Chile, seguido por un maremoto que expulsó barcos grandes y embarcaciones pesqueras hasta kilómetros tierra adentro o los sepultó en el océano. Pero, después de la destrucción inicial, surgió un espectro que creció día a día: el bloqueo de las bocas de salida natural de grandes lagos, mientras los ríos afluentes subían su caudal de agua, amenazaba con provocar una inundación que sepultaría la ciudad de Valdivia y poblaciones aledañas. El cauce del río San Pedro creció sin detenerse y empezó a inundar las poblaciones de sus riberas. Equipos de ingenieros, cientos de obreros y batallones militares trabajaron día y noche, en el barro, bajo lluvia y frío inclementes, hasta que lograron, al cabo de dos meses, abrir una salida controlada a la zona lacustre. Durante ese período de alarma pública, con maniobras progresivas para trasladar las poblaciones ribereñas a sitios en mayor altura, se requería la colaboración de misiones de ayuda, particularmente en salud. En un operativo organizado por el Ministerio de Salud y la Facultad de Medicina de la Universidad de Chile, un grupo de estudiantes que cursaban las últimas semanas del internado, se trasladó a la ciudad de Valdivia. En el Ministerio de Salud recibieron sesiones de entrenamiento previo (un día) en que se les explicaron las responsabilidades que deberían asumir en los sitios más damnificados, las condiciones particulares en que encontrarían a su población, el impacto psicológico que significaría para ellos la espera del resultado de las maniobras que precedían a una eventual evacuación total de Valdivia. Se los equipó con impermeables, botas, sacos de dormir, cantimploras, linternas, medicamentos y equipos básicos de atención y se les trasladó por la única ruta disponible en ese momento: vía aérea desde el aeropuerto de Los Cerrillos. El grupo de internos fue encabezado por un educador sanitario entrenado en psicología de desastres, se los instaló en el gimnasio de una escuela pública donde recibían desayuno y una magra cena nocturna, proporcionados por la $\mathrm{Mu}-$ nicipalidad. Durante el día concurrían a atender la población, reforzando al personal de consultorios de emergencia; en su mayoría fueron destinados a los galpones recién levantados en los potreros de los sectores "Huachocopihue Alto 1 y 2", donde se concentraban las familias evacuadas. Allí vivieron la misma experiencia que relatan sus "pares" en el terremoto actual: necesidades de atención primaria para niños, adultos y ancianos; solicitudes de medicamentos para enfermos crónicos, en reemplazo de los que habían quedado perdidos en sus casas anegadas por el río; patologías respiratorias y digestivas agudas; angustia, depresión, histeria, insomnio. El personal local de salud, incluyendo sus médicos, empezaron a presentar manifestaciones de agotamiento físico y psicológico: algunos "ya no daban más", mientras el nivel del río subía implacable llegando a sus propias casas y sus familias también tenían que refugiarse. Un médico valdiviano acompañaba espontáneamente a los internos durante la cena vespertina, alumbrada por linternas y velas cada vez que se interrumpía la electricidad por las "réplicas" del terremoto. El médico dirigía la conversación relatando lo que había hecho en el día, que era mucho. Su locuacidad fue cotidianamente in crescendo y empezó a confundir situaciones. Una noche irrumpió en el "comedor" y gritó “¿Saben cómo me llamo? ¡Yo soy el héroe 
epónimo de Valdivia! ¿Alguien me contradice?”, junto a lo cual depositó sobre la mesa, con un fuerte golpe, un revólver de respetable tamaño. Al día siguiente, el educador sanitario se comunicó por radio con el Ministerio de Salud y convenció al médico que aceptara ser trasladado en avión a Santiago, "porque se le requería en comisión de servicio para informar sobre la situación de salud en Valdivia”... El 23 de julio, el "espectro del Riñihue" fue vencido por sus esforzados contendores, el nivel del río San Pedro se estabilizó, llegó más ayuda y los internos de Medicina retornaron a la capital...

Estos relatos rara vez aparecen en la historia escrita. Tienen el mérito de describir cómo distintas generaciones de profesionales médicos y de colaboración reaccionan de manera similar ante los cataclismos que con penosa frecuencia ponen a prueba la supervivencia y el bienestar de nuestros compatriotas, así como a nosotros mismos.

Hemos recibido múltiples expresiones de preocupación y apoyo a nuestras instituciones y a nuestras familias, las que agradecemos cordialmente. A la Revista Médica de Chile han llegado mensajes electrónicos de colaboradores y lectores de países de las Américas, Europa y Australia. Un colega argentino terminó su simpático mensaje aludiendo a que "Ustedes, los chilenos, mal que mal ya están acostumbrados a estos desastres". La respuesta, ciertamente tan afectuosa como su mensaje, terminó diciéndole "Es verdad, pero esta es una de las costumbres que nos gustaría mucho poder abandonar".

Ahora, como profesionales de la Salud, debemos afrontar una etapa delicada: la de los efectos psicológicos a mediano y largo plazo originados por el estrés post traumático ${ }^{2}$ y los riesgos de salud física derivados de las condiciones sanitarias alteradas por el sismo. Pero podemos contar con la solidaridad, el altruismo, la voluntad y la experiencia de muchos ciudadanos para lograr que Chile se ponga nuevamente de pie.

\section{Referencias}

1. O’Ryan M. Reflexiones y sentimientos desde un equipo de voluntarios del Ministerio de Salud y el Colegio Médico de Chile, después del terremoto reciente. Rev Med Chile 2010; 138: 270-3

2. Figueroa RA, Marín H, González M. Apoyo psicológico en desastres: Propuesta de un modelo de atención basado en revisiones sistemáticas y metaanálisis. Rev Med Chile 2010; 138: 143-51. 